\title{
LA ASTRONOMÍA AL SERVICIO DEL CONTRIBUYENTE
}

\author{
Enrique Alonso \\ Dept. de Antropología, Lógica y Fia de la Ciencia, Facultad de Filosofía, UNED.
}

V. Clube y B. NAPIER, El Invierno cósmico (traducción de M. Sellés), Madrid, Alianza Editoral, LB 1721, 450pp.

1. Un peculiar género literario.- Sólo unos pocos incautos pueden creer que la Ciencia conserva en la actualidad el valor y la estimación pública que llegó a alcanzar hace tan sólo unas décadas. Más que deducir este dato de las declaraciones de sus protagonistas, poco fiables si se quiere por interesadas, lo obtenemos al comprobar la importancia que ciertas actitudes están adquiriendo dentro de la comunidad científica. La creciente atención que el investigador profesional dedica a convencer al gran público del valor e interés de su disciplina particular y a hacerlo además en unos términos que el hombre común entienda, lo ilustra a la perfección. Aunque es cierto que aulas y laboratorios siguen repletos de una audiencia hipotéticamente interesada todos sabemos que el protagonismo ya no recae sobre el profesional de la ciencia, sino sobre ese espectador cuya presencia no puede permitirse el lujo de perder. Este escenario parece el responsable mediato de la reaparición de un género literario que intenta combinar en un digesto asequible la divulgación científica con la vindicación de alguna disciplina particular. Victor Clube y Bill Napier nos ofrecen en su Invierno Cósmico un ejercicio de divulgación protesta que contiene prácticamente todas las notas estilísticas del género.

La influencia que el entorno cósmico ejerce sobre nuestro planeta es discutida desde las tesis de un catastrofismo poco usual que se presenta como una auténtica y genuina revolución en ciernes. Y como a tan alto fin le corresponden unos medios no menos elevados, nada impide que sea la simulación de un impacto meteórico cataclísmico el que excite nuestra imaginación y la predisponga desde las primeras páginas de la obra a recibir una cascada de argumentos supuestamente convincentes. Para ello no resulta excluida ninguna teoría en particular, todas pueden aportar sus propias evidencias para poner de manifiesto la realidad de un problema que, eso sí, sólo una de estas disciplinas es capaz de resolver adecuadamente. Nos referimos, cómo no, a la astronomía y más en concreto, a lo que nos atreveríamos a bautizar como astronomía catastrófica. Es en este carácter pretendidamente erudito donde mejor se aprecia cómo la reivindicación se impone sobre los preceptos de la buena divulgación poco proclive a ejercicios de síntesis de proporciones tan notables. Podemos imaginar la angustia del traductor, M.A. Sellés, sometido a una continua labor de documentación derivada de la prolija cascada de citas no limitadas por niguna constricción disciplinar. Esto, unido a una redacción a veces tortuosa del original inglés hace de la edición española un 
trabajo notable poco apetecible para cualquier traductor que aprecie su ocio por encima de su dedicación: por fortuna no es el caso de M.A. Sellés.

Sobre estas imposiciones estilísticas vemos alzarse un obra cuyos peores defectos residen no tanto en sus tesis, atractivas y excitantes las más de las veces, sino en una intencionalidad excesivamente pujante en la hilatura interna de sus argumentos. ¿Pero quién puede decir hoy en día que sus razones están completamente al margen de sus intereses?

2. La tesis y las fuentes.- Hace algo más de una década que el catastrofismo viene marcando las grandes líneas de investigación en Ciencias de la Tierra. No es preciso por tanto disponer de una gran cultura para asociar un elemento como el iridio - de utilidad menos conocida- a un fenómeno tan notable como el supuesto impacto cometario que precipitó la última de las grandes extinciones de especies vivas. Este modelo de intervención cósmica se caracteriza por su excepcionalidad, magnífico efecto, capaz de afectar de forma casi instantánea todos los aspectos del equilibrio planetario, y finalmente, por una probabilidad cíclica de período extraordinariamente largo. Se trata pues de un género de catástrofe compuesta por episodios aislados de inmensa repercusión aunque sumamente raros —admitiéndose períodos que oscilan entre los 50, 30 y 15 m.a.- La tesis que Clube y Napier sostienen en esta obra - apoyada en parte sobre su anterior The Cosmic Serpent- consiste en sobreponer un catastrofismo atenuado sobre el modelo episódico mencionado de tal modo que resulte posible extender el paradigma catastrofista a períodos de tiempo muchísimo más cortos. Dicho de forma considerablemente menos política, su tesis pretende hacer uso del temible efecto del medio cometario circundante para explicar ciertos fenómenos y periodicidades apreciables en la evolución de la civilización desde su mismo nacimiento, y, aunque nos pueda parecer excesivo, de ese mismo nacimiento.

La magnitud y vehemencia de muchas de las afirmaciones defendidas en esta obra siembran la duda acerca de cuál es la explicación y qué es lo que debe ser explicado. Si en última instancia lo que se desea es implicar a todo trance la conducta de nuestro entorno celestial en los asuntos humanos, entonces parece evidente que es el primero el que acabará adoptando el aspecto caótico y turbulento del pulso de la civilización aunque sin llegar, claro está, a desbaratar todo progreso. El catastrofismo moderado que se postula adquiere finalmente la conducta de un Olimpo cuyos habitantes divinos son responsables tanto de la llama de la civilización como del fuego que destruye sus excesos. Desgraciadamente, no nos hallamos en condiciones de juzgar si las causas naturales en que se apoya la hipótesis catastrofista de Clube y Napier son sufientemente sólidas como para sostenerla de forma independiente. El poco espacio dedicado a su defensa así como el presumible carácter técnico de las mismas deja ese juicio al alcance tan sólo del experto avisado de tales desarrollos. Sea como fuere, es el tránsito del Sol a través del brazo de la galaxia en que orbita el que genera la marea responsable de los desequilibrios periódicos en la nube cometaria que circunda nuestro sistema. Esa marea provocaría tanto la colisión de grandes cuerpos con la Tierra -impactos cataclísmicos de ciclo largo- como la fragmentación de otros hasta formar un enjambre de bólidos y polvo cósmico. El tránsito de la Tierra a través de uno de esos enjambres se produciría de acuerdo con períodos de ciclo corto y tendría el efecto de una fuerte actividad de impactos de menor cuantía repartidos a lo largo de varios siglos. Esos impactos, junto con la continua deposición de polvo cósmico, provocaría tanto una actividad meteórica apreciable como un enfriamiento considerable del clima - debido a la absorción lumínica imputable al polvo circundante. Esa combinación de factores ofrece el tipo de efecto que permite defender las tesis de un catastrofismo de dimensiones culturales. 


\section{ENSAYOS}

Por peculiar que nos pueda parecer, la tesis de un catastrofismo tal no tendría por qué resultar implausible en un momento en que el catastrofismo, como doctrina general, es bien aceptado. Pero en lugar de trabajar esa sutil disposición del juicio, Clube y Napier cruzan de un salto las fronteras de la divulgación y la apología científicas para buscar auxilio en la mitología y en la interpretación de los relatos de la Historia. Toman asiento así junto a los mitólogos y arqueólogos esotéricos que durante estas últimas décadas han reconstruido la Historia antigua hasta hacer de ella un relato de ciencia-ficción en la que la visita extraterrestre, entre otras cosas, se interpreta como la norma. Pero cada cual elige sus compañeros de viaje y a nosotros nada nos queda decir salvo preguntarnos por las razones de una decisión tan poco oportuna. Tal vez Clube y Napier hayan minimizado la dureza con que se disputa el monopolio de la explicación del mito y los relatos que acompañan la fundación de las antiguas religiones. Pero si el esoterismo y su entorno es fuente de malas compañías, la antropología cultural lo es de malos enemigos. Es una causa difícil, por tanto, buscar en relatos tales como la invasión de los heráclidas la representación mítica de un episodio de bombardeo cósmico, ni en postular que la caída del Imperio Medio a manos de los hicsos pueda guardar relación con uno de esos mismos acontecimientos celestiales. El peor defecto de esta obra es posiblemente su radical equívoco en cuanto al tipo de tesis que debe sumar en su favor. Una reconstrucción naturalista del mito, incapaz de ver en ese fenómeno nada distinto del relato impreciso de fenómenos expresamente observables, no da noticia de un razonamiento abierto a realidades ajenas a un empirismo de poca monta.

3. Sugerencias y provocaciones.- Si se hubiese dejado a un lado el detalle de los acontecimientos renunciando a explicar cualquier crisis de civilización o cualquier relato mítico en el que aparezca mención a cielos e infiernos, la tesis catastrofista expuesta habría conseguido parte de lo que parece su intención: provocar a la comunidad con hipótesis dignas de estudio. Uno de los efectos del tránsito terrestre a través de la nube cometaria en período de actividad sería mostrar, según nuestros autores, un cielo nocturno de características muy distintas al actual. Junto con la Vía Láctea se apreciaría una banda iluminada por la reflexión imputable al polvo cósmico ubicada en la franja zodiacal. Esa franja se vería transitada por bólidos de temible apariencia y de periodicidad indeterminada. Todo ello configuraría una realidad natural poco sometible a regularidades y manifiestamente dispuesta a intervenir por medio de signos y grandes prodigios. A este cielo antiguo le seguiría uno nuevo esencialmente inactivo en el que la banda zodiacal sería poco observable y en el que los planetas habrían pasado al primer plano del protagonismo. Este tránsito se habría confirmado ya en la época clásica del pensamiento griego y continuaría hasta nuestros días. El nuevo cielo correspondería a un tipo de realidad natural bien dispuesta ante la regularidad de los fenómenos, básicamente no intervencionista y capaz por tanto de dejar a la razón un campo de progreso ocupado antes por el relato de acción - las apariciones de bólidos en la franja zodiacal- y el desentrañamiento de la voluntad de los dioses. Ese tránsito alcanzaría su máximo esplendor con Newton cuyo universo es, pese al reconocimiento de los cometas, un medio estéril que deja los asuntos humanos a la actuación de causas y motivaciones sólo humanas. Este vertiginoso proceso de la razón sólo ha empezado a verse alterado en los albores de la era espacial al descubrir un entorno cercano mucho más complejo y activo de lo esperado.

Es nuestra impresión que todas estas tesis podrían haber sido defendidas con mucha mayor eficacia desde una posición mucho más serena y relajada. Si las consideramos en su valor intrínseco apreciamos que su capacidad para suscitar interés queda mermada por la sistemática sobrecactucación que Clube y Napier les imponen a lo largo de esta obra. Una vez más la pregunta es ¿por qué? 


\section{ENSAYOS}

4. Propaganda.- Como ya hemos dicho, el principal defecto de esta obra es imputable a su tono más que a su contenido. La insistencia por acaparar instancias confirmatorias, la continua advocación salvífica con que se celebran sus conjeturas hacen pensar en una manifiesta campaña de sensibilización llevada con la ingenuidad que sólo los científicos profesionales son capaces de mostrar. Por ello resulta pertinente mencionar que tanto Clube como Napier pueden ser identificados como astrónomos ligados al más alto nivel al Real Observatorio de Edimburgo hecho que, a nuestro juicio, influye decisivamente en el tipo de problema planteado en la obra. Un repaso distanciado de sus contenidos provoca la intensa impresión de que el mal descrito adopta las características propias del remedio disponible. Resulta así que la mirada que el astrónomo profesional puede lanzar a los cielos tiene la textura precisa para prevenir o al menos avisar de un tipo de desastre imperceptible para vocaciones más populares. Ni las Ciencias de la Tierra, preocupadas en los cataclismos de nuestro subsuelo, ni la pujante y atractiva astrofísica, sólo atenta a efectos de magnitud inconcebible, pueden atender las demandas de un riesgo inherente, según Clube y Napier, a nuestra presencia en los cielos.

Esta reivindicación de la tarea del astrónomo ha sido guiada de forma tan inexperta que a despecho de las insinuaciones y tesis valiosas contenidas en la obra apenas podemos tomarla como algo más serio que un síntoma, y uno preocupante, del estado actual de la ciencia profesional de envergadura. 